\title{
Chimeric Antigen Receptor T-Cell Therapy
}

National Cancer Institute

\section{Source}

National Cancer Institute. Chimeric Antigen Receptor T-Cell Therapy. NCI Thesaurus. Code C126102.

Treatment that uses T-cells that have been eng ineered to contain a chimeric antigen receptor (CAR) that specifically targets a particular antigen. 